\title{
Enzymatic Processes to Unlock the Lignin Value
}

\author{
Veera Hämäläinen, Toni Grönroos, Anu Suonpää, Matti Wilhem Heikkilä, Bastiaan Romein, \\ Petri Ihalainen, Sara Malandra and Klara R. Birikh*
}

MetGen Oy, Kaarina, Finland

\section{OPEN ACCESS}

Edited by:

Arthur Jonas Ragauskas, University of Tennessee,

United States

Reviewed by:

Marcus Foston,

Washington University in

St. Louis, United States

Bing-Zhi Li,

Tianjin University, China

*Correspondence:

Klara R. Birikh

klara@metgen.com

Specialty section:

This article was submitted to

Bioenergy and Biofuels,

a section of the journal

Frontiers in Bioengineering

and Biotechnology

Received: 31 October 2017

Accepted: 19 February 2018

Published: 22 March 2018

Citation:

Hämäläinen V, Grönroos T, Suonpää A, Heikkilä MW, Romein B, Ihalainen P, Malandra $S$ and Birikh KR

(2018) Enzymatic Processes to

Unlock the Lignin Value.

Front. Bioeng. Biotechnol. 6:20. doi: 10.3389/fbioe.2018.00020
Main hurdles of lignin valorization are its diverse chemical composition, recalcitrance, and poor solubility due to high-molecular weight and branched structure. Controlled fragmentation of lignin could lead to its use in higher value products such as binders, coatings, fillers, etc. Oxidative enzymes (i.e., laccases and peroxidases) have long been proposed as a potentially promising tool in lignin depolymerization. However, their application was limited to ambient $\mathrm{pH}$, where lignin is poorly soluble in water. A Finnish biotechnology company, MetGen Oy, that designs and supplies industrial enzymes, has developed and brought to market several lignin oxidizing enzymes, including an extremely alkaline lignin oxidase MetZyme ${ }^{\circledR}$ LIGNOTM $^{\mathrm{T}}$, a genetically engineered laccase of bacterial origin. This enzyme can function at $\mathrm{pH}$ values as high as 10-11 and at elevated temperatures, addressing lignin at its soluble state. In this article, main characteristics of this enzyme as well as its action on bulk lignin coming from an industrial process are demonstrated. Lignin modification by MetZyme ${ }^{\circledR}$ LIGNO ${ }^{\mathrm{TM}}$ was characterized by size exclusion chromatography, UV spectroscopy, and dynamic light scattering for monitoring particle size of solubilized lignin. Under highly alkaline conditions, laccase treatment not only decreased molecular weight of lignin but also increased its solubility in water and altered its dispersion properties. Importantly, organic solvent-free soluble lignin fragmentation allowed for robust industrially relevant membrane separation technologies to be applicable for product fractionation. These enzyme-based solutions open new opportunities for biorefinery lignin valorization thus paving the way for economically viable biorefinery business.

Keywords: oxidoreductase, laccase, lignin, biomass, lignocellulosic, enzyme

\section{INTRODUCTION}

In the biorefinery context, lignin is often mostly regarded as a recalcitrance factor, fermentation inhibitor, sugar stream contaminant, etc. Broader view to the biorefinery, however, considers valorization of lignin a vital component of the economics of the entire concept.

Today, the commercial sales of lignin are limited but growing. Even though the pulp and paper industry produces about 50 million tons of lignin in a year, as defined by Lux Research (Essery, 2017), most of this is burned for power; only 1 million ton reaches the chemicals market. Lignin is currently being used for low- and medium-value applications (e.g., binding and dispersing agents), representing a market of $\$ 730$ million. As detailed by Lux Research report (Lux, 2014), the total market value for lignin-derived product is at $\$ 3.3 \mathrm{~B}$, with energy capturing about $89 \%$ of the market. Other markets include vanillin production $(\$ 192 \mathrm{M})$ and cement additives $(\$ 176 \mathrm{M})$. The market has 
both high-value applications, such as carbon fibers and phenols, as well as lower value applications such as binders and activated carbon. The lowest value use of lignin is its use as solid fuel as energy content of the lignin is in the range of $22 \mathrm{MJ} / \mathrm{kg}$.

The growing need for lignin to produce renewable biochemicals from lignocellulosic feedstocks alone is projected to grow up to 2.9 million Mton in 2017. Potential market value of new ligninbased products is estimated to be about $\$ 13.9 \mathrm{~B}$ by $2020-2025$, with lignin-based phenols and carbon fiber poised to capture the largest market potential in the future (Frost and Sullivan, 2014; Smith et al., 2016).

Main hurdles of lignin valorization are its diverse structure and poor solubility. Liquefaction of lignin would allow its use as fuel, as it is reached in high-energy chemical structures. More precise depolymerization or fragmentation of lignin may enable higher value products for various industries from construction to high-performance materials. Notwithstanding the fact that lignin-based replacement products have already been reported (Gandini and Belgacem, 2008; Kim and Kadla, 2010; Laurichesse and Avérous, 2014; Xing et al., 2017) to be useful as binders, coatings, and fillers and others, these applications are not yet widely industrially implemented. Some of the main challenges for full valorization of lignin are the economical production of suitable lignin and maintaining consistent quality throughout different batches.

To achieve desirable properties for the industrial application, lignin usually needs to be fragmented to a lower molecular weight and often chemically modified as well. Some chemomechanical methods for lignin depolymerization have been reported (Rinaldi et al., 2016). Different ways to convert lignin to phenolics compounds are liquefaction (Kang et al., 2013), oxidation (Ma et al., 2014), solvolysis (Kleinert and Barth, 2008), hydrocracking (Yoshikawa et al., 2013), and hydrolysis (Roberts et al., 2011). The challenge, however, is that lignin is very difficult to decompose and these processes generate high amounts of solid residue.

Enzymatic degradation of lignin, which occurs in nature, was speculated for a long time to be applicable in the industry (Wong, 2009). This approach seems attractive due to the fact that the catalysis takes place in water and under mild conditions avoiding high pressure, temperatures, and hazardous and expensive chemical catalysts, thus saving CAPEX and lowering environmental impact.

Research efforts for enzymatic lignin depolymerization were especially focusing on laccases (copper oxidases), as these enzymes require no cofactors or cosubstrates (such as hydrogen peroxide), they use oxygen as an electron acceptor and produce water as the only by-product. Prospective and challenges of laccase application in biotechnology were recently reviewed (Roth and Spiess, 2015; Mate and Alcalde, 2017).

Industrially available and most studied laccases are fungal enzymes. These enzymes, however, efficient, mostly work in acidic pH (Rodgers et al., 2010), at which lignin is hardly soluble in water. In addition, fungal enzymes lack the needed thermostability and robustness.

Some studies addressed the feasibility of using these laccases for lignin depolymerization (Munk et al., 2015); however, special measures need to be taken to bring lignin into the soluble state. To this end, laccases were evolved to be used in solvent containing mixtures, ionic liquids, and other technically and economically challenging environments (Mate and Alcalde, 2014; Rehmann et al., 2014). To the best of our knowledge, none of these studies led to an industrially viable enzymatic process for lignin valorization. Alternatively, lignin can be efficiently solubilized in water under alkaline $\mathrm{pH}$. The higher the $\mathrm{pH}$, the higher the lignin solubility. This phenomenon could be exploited in enzymatic depolymerization, where laccases able to function under these conditions.

Bacterial laccases are rather overlooked by the industries due to challenges in their production and lower redox potential as compared to fungal laccases. However, they are also known for larger diversity in operation conditions, including higher thermostability and extended $\mathrm{pH}$ range (Santhanam et al., 2011; Rosado et al., 2012). In this respect, they may represent an alternative route to lignin depolymerization-that is by carrying out the process under alkaline conditions.

One of the challenges in laccase application for lignin depolymerization as noted by many experts is the fact that the strong polymerization activity of laccase counters the decomposition of lignin by re-polymerizing the degradation products (Roth and Spiess, 2015). It was postulated (Hahn et al., 2014) that the balance between polymerization and cleavage reactions depend on the structure and redox potential of the laccase, structure and redox potential of the substrate, $\mathrm{pH}$ value of the buffer used, incubation temperature, and solvent concentration. Thus, thorough process development is required for directing the reaction into the desired path (Santhanam et al., 2011; Singh et al., 2015). This notion also implies that finding a laccase highly efficient in oxidizing phenolic compounds is not necessarily instrumental for lignin depolymerization. In our experience, highly alkaline $\mathrm{pH}$ is more favorable for depolymerization, than acidic conditions.

It has to be noted that even in alkaline conditions lignin may have limited solubility which results in relatively low product titer when compared with chemical processes. Besides, timescale of the enzymatic oxidation poses a challenge, which may be eventually overcome by a continuous process setup with reusable enzyme. Application testing in relevant experimental setup is necessary to evaluate the industrial relevance.

In this study, we present a genetically engineered commercially produced bacterial laccase which is functional and stable at $\mathrm{pH}$ as high as $10-11$ and demonstrate its use in reactor-scale lignin depolymerization.

\section{MATERIALS AND METHODS}

\section{Enzyme Activity Testing with Standard Substrates}

Relative laccase activity at different $\mathrm{pH}$ with standards substrates, 2,2'-Azino-bis(3-ethylbenzthiazoline-6-sulfonic acid) (ABTS), syringaldazine (SGZ), and 2,6-dimethylphenol (DMP), were determined as follows. Substrates were prepared as $10 \times$ stock solutions: $50 \mathrm{mM}$ ABTS and $10 \mathrm{mM}$ DMP in water and $250 \mu \mathrm{M}$ 
SGZ in methanol. Enzyme was diluted to provide linear product accumulation during the reaction time. Reaction mixtures were prepared by adding $10 \mu \mathrm{l}$ of enzyme to $170 \mu \mathrm{l}$ of $30 \mathrm{mM}$ Britton \& Robinson buffer ( $\mathrm{pH} 2-11$ ) and equilibrated to room temperature in a 96-well microtiter plate. The enzymatic reactions were initiated by adding $20 \mu \mathrm{l}$ of substrates solutions and oxidation of substrates was followed by monitoring absorbance at $405 \mathrm{~nm}$ for ABTS, $450 \mathrm{~nm}$ for DMP, and $530 \mathrm{~nm}$ SGZ. Relative reaction rates were calculated from the absorbance increase vs time.

Specific enzyme activity was determined using ABTS as substrate. Reaction mixture was prepared by mixing $20 \mu \mathrm{l}$ of diluted enzyme with $430 \mu \mathrm{l}$ of $100 \mathrm{mM}$ sodium acetate $\mathrm{pH} 4.5$ in 1-cm light-path spectrophotometer cuvette, the mixture was equilibrated to $60 \mathrm{C}$; the reaction was initiated by adding $50 \mu \mathrm{l}$ of ABTS solution and incubated at $60 \mathrm{C}$; UV measurements at $405 \mathrm{nM}$ were performed every $2 \mathrm{~min}$. One unit of laccase activity was defined as the enzyme amount oxidizing $1 \mu \mathrm{mol}$ of ABTS per minute under these conditions (whereas extinction coefficient of ABTS at $405 \mathrm{~nm}$ is $36,800 \mathrm{M}^{-1} \mathrm{~cm}^{-1}$ ). One microkatal is the amount of enzyme oxidizing $1 \mu \mathrm{mol}$ of substrate per second, hence $1 \mu$ kat equals to $60 \mathrm{U}$.

\section{Laccase Stability Testing}

Laccase stability at different $\mathrm{pH}$ was determined by pre-incubation of the enzyme at a certain temperature and $\mathrm{pH}$, followed by measurement of residual activity.

For this, $20 \mu \mathrm{l}$ of enzyme was added to $180 \mu \mathrm{l}$ of $150 \mathrm{mM}$ Britton \& Robinson buffers with the desired $\mathrm{pH}$ (9-11) preequilibrated to the desired temperature, incubation was continued for the desired time. Samples of $10 \mu \mathrm{l}$ were taken at certain time points (starting from time 0 ) and immediately added to $170 \mu \mathrm{l}$ of $100 \mathrm{mM}$ sodium acetate buffer $\mathrm{pH} 4.5$ in a 96-well microtiter plate and kept on ice. When all the time-point samples were collected, enzymatic reactions in the microtiter plate were started by adding $20 \mu \mathrm{l}$ of $50 \mathrm{mM}$ ABTS solution, and relative reaction rates were determined by monitoring absorbance at $405 \mathrm{~nm}$ vs time.

\section{Alkali Soluble Lignin Preparation}

Hardwood lignin extracted by extrusion-based process was obtained from an industrial source (http://sweetwater.us/process/). As reported by the manufacturer, the molecular weight is $\mathrm{Mn}=2,700-4,000 \mathrm{~g} / \mathrm{mol}, M_{\mathrm{w}}=7,500-8,280 \mathrm{~g} / \mathrm{mol}, \mathrm{PDI}=2.2-3.0$, and the hydroxyl content is $2.85 \mathrm{mmol} / \mathrm{g}$ aliphatic $-\mathrm{OH}$ (possibly carbohydrates), $0.9 \mathrm{mmol} / \mathrm{g}$ syringyl $-\mathrm{OH}, 0.53 \mathrm{mmol} / \mathrm{g}$ guaiacyl $\mathrm{OH}, 0.1 \mathrm{mmol} / \mathrm{g}$ phenolic $\mathrm{OH}$.

Alkali soluble lignin was prepared as follows: lignin was solubilized at $100 \mathrm{~g} / \mathrm{l}$ in $0.25 \mathrm{M} \mathrm{NaOH}$, mixed for $30 \mathrm{~min}$ at room temperature, centrifuged at $6,000 \mathrm{~g}$ for $20 \mathrm{~min}$, supernatant was dried in oven at $105 \mathrm{C}$, and stored at room temperature until used. Drying of lignin after alkaline solubilization was not essential for laccase oxidation, it was performed for convenience in storage and obtaining reproducible results with different batches of lignin. For the laccase treatment, dried alkaline soluble lignin was dissolved at $25 \mathrm{~g} / \mathrm{l}$ in water (solubilization was complete) and $\mathrm{pH}$ adjusted to 10.5 .

\section{Lignin Depolymerization with Laccase MetZyme $^{\circledR}$ LIGNO $^{\text {TM }}$}

Alkaline soluble lignin prepared as described earlier was dissolved in water to the final concentration $25 \mathrm{~g} / \mathrm{l}$. The reactions were run in 11 twin-pot bioreactor (BIOSTAT ${ }^{\circledR} \mathrm{B}$ plus twin from Sartorius Stedim Biotech). Mediator syringaldehyde was added $0.1 \% \mathrm{w} / \mathrm{w}$ in respect to lignin and the reactor equilibrated to $50^{\circ} \mathrm{C}$, and $\mathrm{pH} 10.5$ with aeration $0.16 \mathrm{l} / \mathrm{min}$. After that, the enzyme was added $80 \mathrm{nkat} / \mathrm{g}$ of lignin ( $\sim \mathrm{U} / \mathrm{g}$ of lignin). Control reaction was run without the enzyme-further throughout the text referred to as "Control lignin" or "Control sample." Reaction was continued for $21 \mathrm{~h}$ with constant aeration $(0.16 \mathrm{l} / \mathrm{min}$, dissolved oxygen level was remaining constant from the time of enzyme addition), $\mathrm{pH}$ was controlled with $\mathrm{NaOH}$ to remain 10.5 throughout the reaction.

\section{Size Exclusion Chromatography}

Size exclusion chromatography for lignin samples and molecular weight standards was performed using HPLC chromatographer 120 CompactLC with UV detector (Agilent Technologies), equipped with size exclusion column MCX 1,000 $5 \mu \mathrm{m}$, $8 \mathrm{~mm} \times 300 \mathrm{~mm}$ and with pre-column MCX $5 \mu \mathrm{m}, 8 \mathrm{~mm} \times 50 \mathrm{~mm}$ (Polymer Standards Service). Isocratic mode with $0.1 \mathrm{M} \mathrm{NaOH}$ eluent flow $0.5 \mathrm{ml} / \mathrm{min}$ at RT was used; run time was $40 \mathrm{~min}$. Lignin samples were monitored at $280 \mathrm{~nm}$. Molecular mass standards (polystyrene sulfonate sodium salt standards $\mathrm{Mp}=\sim 0.9$ to $\sim 65 \mathrm{kDa}$, Polymer Standards Service) were monitored at $254 \mathrm{~nm}$. Data were acquired using the EzChrom Elite Compact software.

Primary HPLC traces acquired using the Agilent EZChrom Elite software were transferred to tailor-made MS Excel(R) spreadsheets for further processing. Signal vs retention time graphs were produced from $1 \mathrm{~Hz}$ time series to depict the chromatography traces.

Polystyrene sulfonate molecular mass standards (Polymer Standards Service), ranging in mass at peak maximum from $M_{\mathrm{W}}=\sim 900$ to $\sim 65,000$, and syringaldehyde $\left(M_{\mathrm{W}} 182\right)$ were used for calibration of molecular weights.

Based on HPLC profiles, average molecular weights-number average molecular weight $\left(M_{\mathrm{n}}\right)$ and the weight average molecular weight $\left(M_{\mathrm{w}}\right)$, which emphasizes the contribution of polymers with larger molecular weights, were calculated for lignin fractions.

The $M_{\mathrm{n}}$ was calculated by dividing the total relative polymer weight by the total number of polymer molecules, using the following equation:

$$
M_{\mathrm{n}}=\frac{W}{\sum N_{i}}=\frac{\sum\left(M_{i} N_{i}\right)}{\sum N_{i}}=\frac{\sum\left(H_{i}\right)}{\sum\left(H_{i} / N_{i}\right)} .
$$

The $M_{\mathrm{w}}$ was calculated using the equation:

$$
M_{\mathrm{w}}=\frac{\sum\left(W_{i} M_{i}\right)}{W}=\frac{\sum\left(H_{i} M_{i}\right)}{\sum H_{i}}
$$

where $W$-total weight of polymers, $W_{i}$-weight of i-th polymer, $M_{i}$-molecular weight of the $i$-th elution time, $N_{i}$-number of molecules with molecular weight $M_{i}, H_{i}$-height of $i$-th elution time. 


\section{Demethylation Detection}

Demethylation of lignin was followed by monitoring methanol in the reaction mixture after completion of the oxidation. Purpald method adapted from Anthon and Barrett (2004) was used for detecting methanol. The method is based on conversion of methanol to formaldehyde by alcohol oxidase enzyme and subsequent spectrophotometric quantification of the formaldehyde. Alcohol oxidase from Pichia pastoris and Purpald reagent (4-amino3-hydrazino-5-mercapto-1,2,4-triazole) were purchased from Sigma Aldrich.

Purpald method was adapted to 96-microwell plate (Spectra Plate, Cat. 6005640, Perkin Elmer). Lignin samples were adjusted to $\mathrm{pH} 7.0$ with $\mathrm{HCl}$ and diluted 1:25 with water. Methanol standards $(0-0.5 \mathrm{mM})$ were used. For all lignin samples, negative controls were prepared by adding buffer without alcohol oxidase. Diluted lignin samples $(28 \mu \mathrm{l})$ or methanol standards were pipetted as triplicates into 96 -well plate, and $28 \mu \mathrm{l}$ of $100 \mathrm{mM}$ sodium phosphate buffer $\mathrm{pH} 7$ containing $1 \mathrm{U} / \mathrm{ml}$ alcohol oxidase (solution prepared just before use) was added to the wells. The mixtures were incubated at $30^{\circ} \mathrm{C}$ for $10 \mathrm{~min}$ with $250 \mathrm{rpm}$ shaking (MaxQ 4450, Thermo Scientific). Purpald reagent (34 mM in $0.5 \mathrm{M}$ $\mathrm{NaOH}$ ) was prepared just before use, and $56 \mu$ of Purpald reagent was added to the reactions; the samples were further incubated at $30^{\circ} \mathrm{C}$ for $30 \mathrm{~min}$ with $250 \mathrm{rpm}$ shaking. After that, $168 \mu \mathrm{l}$ of water was added to the wells, mixed for a minute, and absorbance measured at $560 \mathrm{~nm}$ using spectrophotometer (Multiscan Go, Thermo Scientific). The methanol concentrations in the lignin samples were calculated using absorbance values obtained from the calibration curve of methanol standard solutions.

\section{Lignin Solubility Assessment}

Lignin sample after enzyme treatment (or control sample, run without the enzyme) was equilibrated to room temperature and showed initial pH 10.8 (as depolymerization was carried out at $50^{\circ} \mathrm{C}$ at $\mathrm{pH} 10.5$ ). Sample was slowly titrated with $\mathrm{HCl}$ to allow the $\mathrm{pH}$ to stabilize at integer values (10.0, 9.0, 8.0, and so on); aliquots were taken at each of these $\mathrm{pH}$ and frozen. After completing the titration, all samples were thawed at room temperature and allowed to stand for $1 \mathrm{~h}$, after which samples were centrifuged at $18,000 \mathrm{~g}$ for $30 \mathrm{~min}$ and UV absorption was measured in the supernatant to determined soluble fraction. Relative values to the starting material were plotted against the $\mathrm{pH}$.

\section{Lignin Fractions Separation}

For lignin fractions separation, ultrafiltration was performed using tangential flow membrane units Vivaflow 200 (Sartorius) with polyethersulfone membranes with 10 - and 2-kDa cutoff values. The units were used according to the manufacturer's protocol ( 2.5 bar pressure, $200-400 \mathrm{ml} / \mathrm{min}$ retentate flow/module). The ultrafiltration was carried on until penetrate volume reached $90 \%$ of the starting material volume.

\section{Lignin Particles Measurement}

Dynamic light scattering (DLS) measurements were performed at $298 \mathrm{~K}$ using a zetasizer equipment (Model Nano ZS, Malvern, Worcestershire, UK) equipped with a red laser operating at
$632.8 \mathrm{~nm}\left(\mathrm{He} / \mathrm{Ne}\right.$ laser) and the detector positioned at $173^{\circ}$ (noninvasive back scattering technology). The measuring size range of $0.1 \mathrm{~nm}$ to $10 \mu \mathrm{m}$ was applied. The data were analyzed using the Malvern Zetasizer Software v. 7.12. Soluble lignin samples were prepared and treated with the enzyme as described above and diluted 1:100 with $150 \mathrm{mM}$ Britton and Robinson buffer $\mathrm{pH} 10.5$ for the measurement.

\section{RESULTS}

\section{Alkaline Laccase MetZyme ${ }^{\circledR}$ LIGNO $^{\mathrm{TM}}$}

New commercially available genetically engineered bacterial laccase MetZyme ${ }^{\circledR}$ LIGNO $^{\text {TM }}$ (MetGen) was tested with following standard laccase substrates: 2,2'-Azino-bis(3-ethylbenzthiazoline6-sulfonic acid) (ABTS), SGZ, and DMP. Laccase efficiency in oxidizing different substrates depends on both-laccase properties and substrate properties (Rosado et al., 2012), thus optimal $\mathrm{pH}$ needs to be determined for a particular laccase with each substrate. As seen from Figure 1A, the enzyme is able to oxidase phenolic substrate (DMP) at extremely alkaline $\mathrm{pH}$, as high as 11 .

Enzyme stability may be severely compromised in alkaline $\mathrm{pH}$, and standard activity measurements can be misleading, as they are performed in short-time reactions. Enzyme stability at alkaline $\mathrm{pH}$ was evaluated by pre-incubation of the enzyme in a buffer with desired $\mathrm{pH}$ and further testing the residual activity after readjusting the $\mathrm{pH}$ (Figures 1B-D). ABTS was used for residual activity measurement as it provides the highest sensitivity and dynamic range. The enzyme was found to be fairly stable in the tested $\mathrm{pH}$ range at $50^{\circ} \mathrm{C}$, therefore pre-incubation at this temperature was carried out over an extended period of time-24 h (Figure 1B); in other temperatures $1 \mathrm{~h}$ pre-incubation was used.

\section{Treatment of Alkali Soluble Industrial Lignin with MetZyme ${ }^{\circledR}$ LIGNO $^{\mathrm{TM}}$}

Industrial biorefinery lignin obtained from extrusion pretreatment method was used in these experiments. Experiments were performed in a reactor scale and final samples were analyzed by size exclusion chromatography with UV detector set to $280 \mathrm{~nm}$ (Figure 2A). Based on the HPLC profile, molecular weight distribution was obtained using molecular weight standards (Figure 2B). The results show a substantial transformation of the molecular weight distribution toward lower molecular weights.

\section{Properties of Enzyme-Treated Lignin}

Enzyme-treated lignin and control sample were subjected to titration with hydrochloric acid and the acid consumption was recorded throughout the course of the titration (Figure 3A). Enzyme-treated sample showed more extensive buffering in the range of $\mathrm{pH} 9-11$, corresponding to protonation of phenolic hydroxyls, and an additional buffering range around $\mathrm{pH} 8-9$, likely to reflect the presence of $\mathrm{C}$-alpha oxidized phenolic groups as pictured on the graph of Figure 3A (see Discussion).

During the titration, it was observed that enzyme-treated lignin starts to precipitate at much more acidic $\mathrm{pH}$ than control sample. To evaluate this phenomenon, we prepared lignin samples 

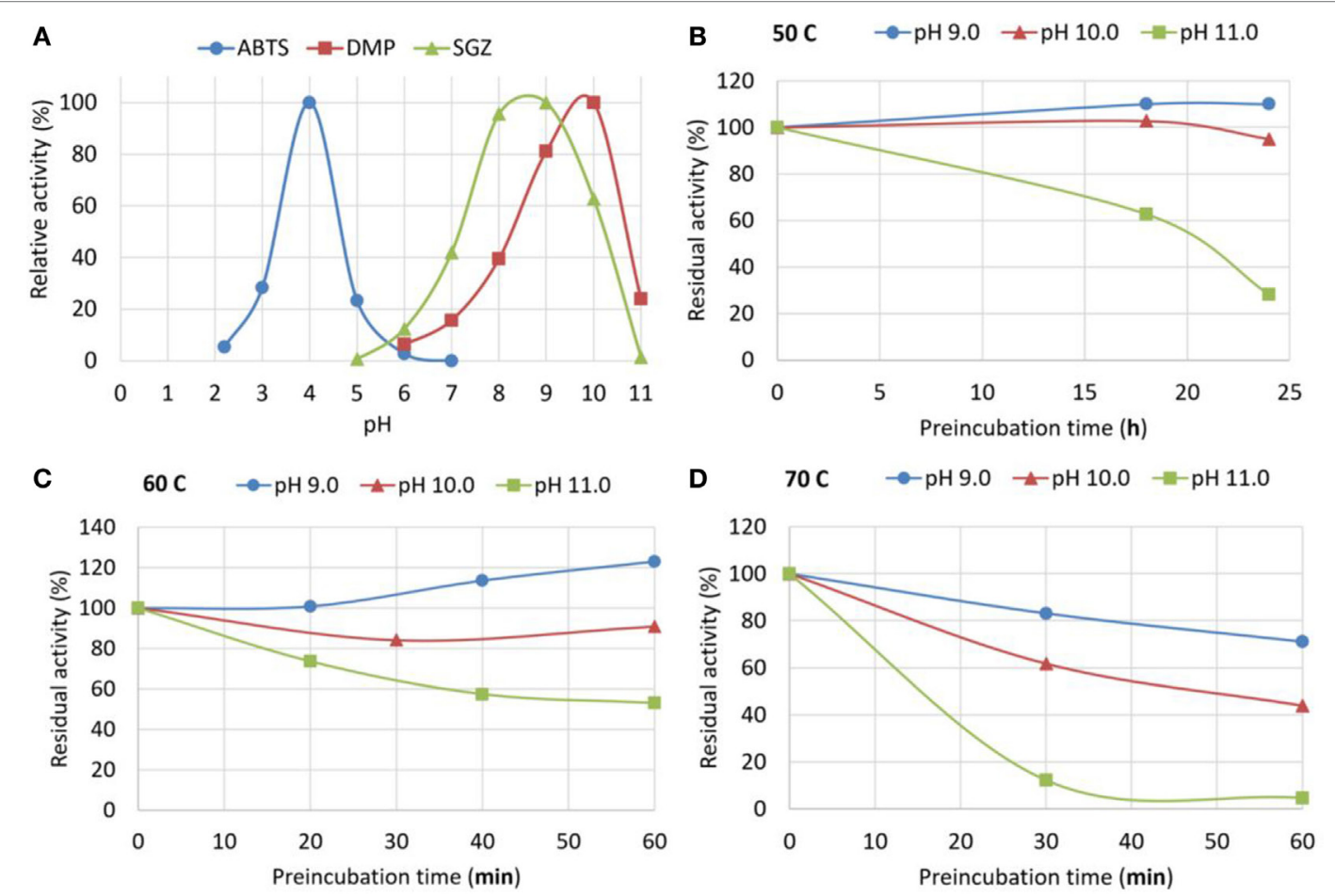

FIGURE 1 | Standard activity and stability of MetZyme ${ }^{\circledR}$ LIGNO ${ }^{\mathrm{TM}}$. (A) pH dependence of MetZyme ${ }^{\circledR}$ LIGNOTM activity toward standard low-molecular weight substrates: 2,2'-Azino-bis(3-ethylbenzthiazoline-6-sulfonic acid) (ABTS), syringaldazine (SGZ), and 2,6-dimethylphenol (DMP). (B-D) Stability of MetZyme ${ }^{\circledR}$ LIGNOTM at various $\mathrm{pH}(9-11)$ and temperatures $\left(50,60\right.$, and $\left.70^{\circ} \mathrm{C}\right)$; pre-incubation time at indicated conditions is plotted against residual activity measured after preincubation. Pre-incubation at $50^{\circ} \mathrm{C}$ was carried out over a span of $24 \mathrm{~h}$, at 60 and $70^{\circ} \mathrm{C}-$ over $1 \mathrm{~h}$; temperatures and pH are indicated over the graphs. The curves do not represent a model fit, they are line interpolations that Microsoft excel provides as a default and they are added only for convenience.

by adjusting the $\mathrm{pH}$ of control and enzyme-treated preparations $(25 \mathrm{~g} / \mathrm{l})$ to different $\mathrm{pH}$ values, and monitored lignin precipitation (Figure 3B). Enzyme-treated lignin remained fully soluble even at $\mathrm{pH} 5.0$, whereas in control sample at this $\mathrm{pH}$ only $35 \%$ of lignin remained in solution.

Oxidative demethylation of lignin is cleavage of aryl ether between phenolic oxygens and methoxy carbons, resulting in formation of a methanol molecule and a new phenolic hydroxyl group. It is a desirable process in lignin upgrade, as it increases the number of hydroxyls and thus results in activation of lignin. Demethylation was monitored by measuring $\mathrm{MeOH}$ in the reaction mixture after depolymerization. The enzyme-treated sample showed $0.47 \mathrm{mmol}$ of $\mathrm{MeOH}$ per gram of lignin as opposed to $0.11 \mathrm{mmol} / \mathrm{g}$ in the control sample. This corresponds to a $30 \%$ increase of total number of phenolic hydroxyls when compared with the starting material as of manufacturer specification $(1.5 \mathrm{mmol} / \mathrm{g})$. It has to be noted that this method may result in some underestimation of the degree of demethylation, as $\mathrm{MeOH}$ is likely to be evaporated during the course of lignin depolymerization in spite of the water condensation unit present in the reactor. Nevertheless, this result confirms an important notion that significant demethylation does take place during this process.

\section{Dynamic Light Scattering}

As it has been shown previously, lignin tends to be dispersed in aqueous medium and the particle size depends on its chemical composition, solubility, $\mathrm{pH}$, and other factors (Nistor et al., 2014). This property is important for evaluating lignin as potential dispersant for industrial applications.

The particle size distribution curves show a clear differentiation between untreated and enzymatically treated lignin (Figure 4). Particle size distribution curve is multimodal in the case of unmodified lignin sample, showing relatively broad main peak at $459 \mathrm{~nm}$ and two other peaks at 68 and 5,560 nm. On the other hand, the enzymatically treated sample shows bimodal distribution with main peak at $142 \mathrm{~nm}$ and lower intensity peak at $28 \mathrm{~nm}$. In addition, the peaks are clearly narrower than those for untreated lignin, suggesting less polydispersity.

The observed differences in the particle size distribution and polydispersity between untreated and enzymatically treated lignin samples indicate an increased solubility and better dispersibility for the latter.

\section{Fractionation of Enzyme-Treated Lignin}

Enzyme-treated lignin was further subjected to ultrafiltration to separate fractions of different molecular weight. The experiment flow chart is depicted in Figure 5A. Fractions were designated with codes (L0 for the extrusion lignin, L1-for alkaline soluble fraction, and so on according to the Figure 5). Further mentioning of these codes refers to the corresponding lignin fractions.

As seen on the photographs (Figure 5A), dried lignin fractions have different color and morphology. Lignin fractions were 

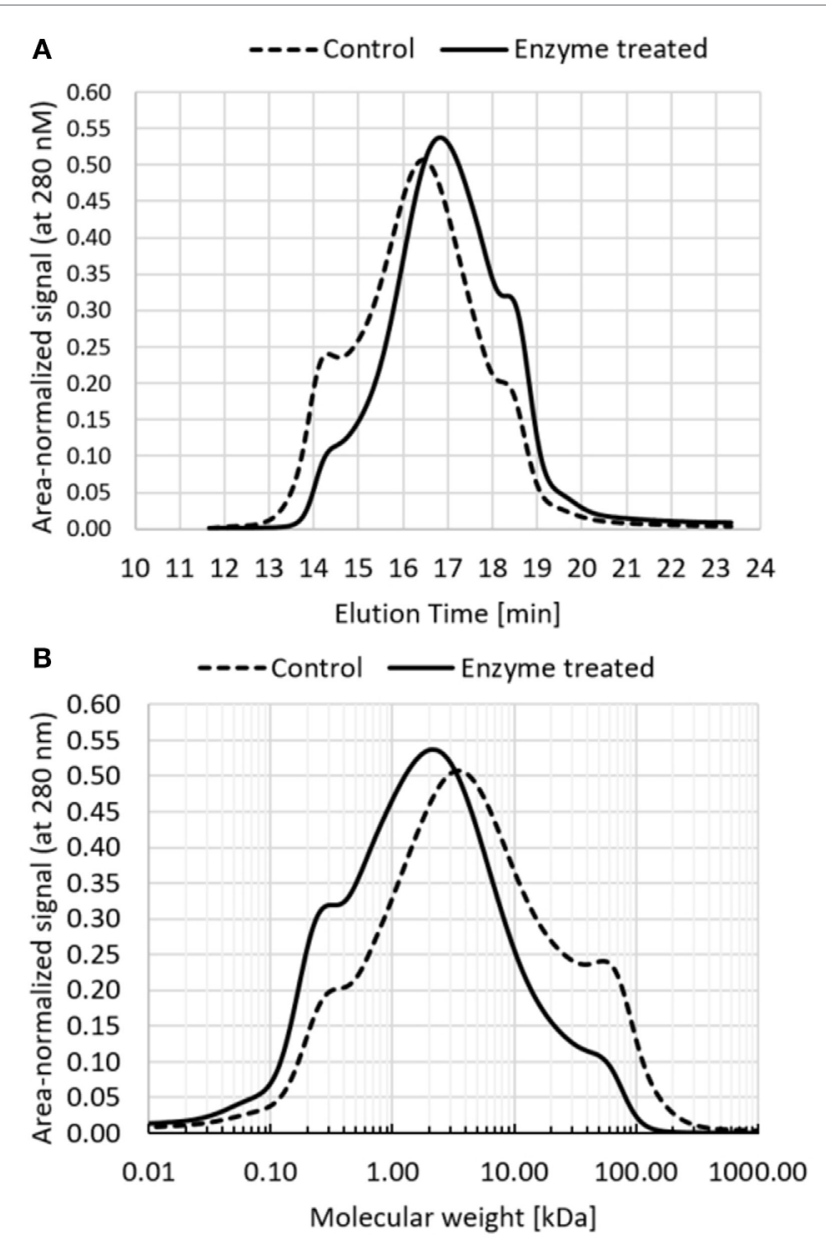

FIGURE 2 | Molecular weight distribution of enzyme-treated lignin sample and control sample (the same process run without the enzyme). (A) Elution profiles of size exclusion chromatography, profiles were area-normalized to reflect the same total mass; (B) molecular weight distribution calculated based on HPLC profile using molecular weight standards.

analyzed by size exclusion chromatography and showed good separation and low dispersity (Figure 5B). Average molecular weights $M_{\mathrm{n}}$, and $M_{\mathrm{w}}$ were calculated for selected fractions. Notably, from this analysis L4 fraction contains predominantly molecules no bigger than trimers. More precise determination of molecular weights of this smallest fraction requires different type of column.

\section{DISCUSSION}

In the view of rising BioEconomy, proper exploitation of lignin through more noble applications than fuel are of vital importance.

The key characteristics of lignin that need to be achieved are unification of its molecular weight and increased reactivity. In addition, the material needs to be transformed to a more manageable form-soluble or melting. These characteristics largely depend on the lignin origin and preparation methods and can be further tuned after lignin separation (Abdelaziz et al., 2016; Rinaldi et al., 2016); this is often referred to as lignin upgrade.
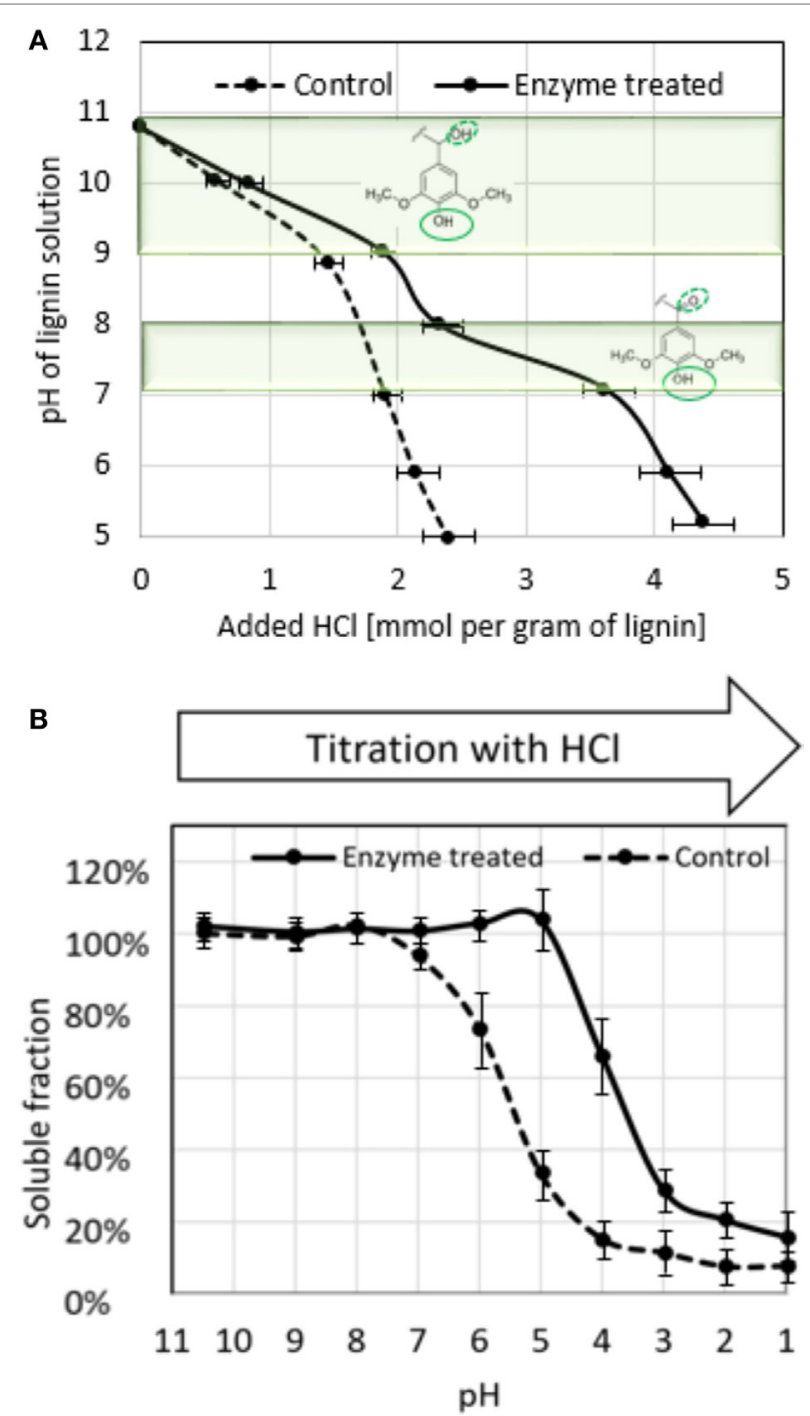

FIGURE 3 | Properties of enzyme-treated lignin revealed from acid titration. (A) Acid titration curve of enzyme-treated and control lignin; highlighted areas indicate $\mathrm{pH}$ ranges of deprotonation of phenolic hydroxyls $(\mathrm{pH} 9-11)$ and phenolic hydroxyls of lignin units with keto group at alpha-carbon (see Discussion), deprotonating hydroxyls in the molecules are outlined with solid line, substituent at alpha-carbon is outlined with dotted line; (B) solubility of enzyme-treated and control lignin at different $\mathrm{pH}$. The results are average of three independent titrations.

Methods for isolation and chemical oxidative upgrade of lignin were recently reviewed by Lange et al. (2013). It is evident that different strategies of lignin valorization have been exploited from trying to preserve its native structure and high-molecular weight to depolymerizing it to monomers (Gouveia et al., 2012; Picart et al., 2017).

It is important to understand that lignin preparations of different molecular weight can be further valorized and utilized in various industrial applications (Gandini and Belgacem, 2008; Laurichesse and Avérous, 2014) as long as chemical/physical properties are matching the requirements (Passoni et al., 2016). Thus, the target of lignin depolymerization is to create lignin fractions 


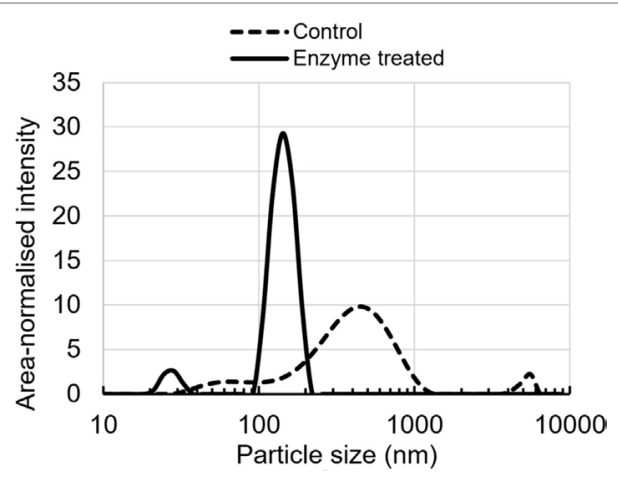

FIGURE 4 | Colloidal particle size distribution of enzyme-treated and control lignin in a buffer at $\mathrm{pH} 10.5$.

that are bioequivalent, for example, to oil-based compounds used as resins, adhesives, composites, and foams (Table 1). Generally, if higher value chemicals are wanted to be replaced, stricter molecular weight distributions are required-reachable via enzymatic lignin depolymerization. In this view, it is not necessarily desirable to depolymerize lignin to monomers in its entirety. We believe that it is beneficial from the economic and environmental point of view to pursue a less energy intensive transformation of the starting material, followed by efficient separation, which will provide valuable fractions for various applications. In this view, enzymatic approach seems very attractive.

In this study, for the first time, enzymatic treatment of bulk industrial lignin was demonstrated at extremely alkaline conditions, where lignin is soluble in water.

This has become possible due to a new industrial genetically evolved laccase of bacterial origin with exceptional properties. As demonstrated in Section "Results," the enzyme retains full activity after $24 \mathrm{~h}$ incubation at $50^{\circ} \mathrm{C}$ at $\mathrm{pH} 10$ and $30 \%$ activity at $\mathrm{pH} 11$.

In a one-liter bioreactor scale, extensive lignin depolymerization was observed, accompanied by chemical activation via demethylation and benzylic oxidation as well as increased solubility in neutral and acidic $\mathrm{pH}$ and altered colloidal behavior. In the view of recent advancements in using lignin nanoparticles for grafting synthetic polymers and manufacturing thermoplastic composites, the particle size decrease and unification that we observed in enzyme-treated samples may be advantageous for this technology (Hilburg et al., 2014).

In the course of process optimization, we observed that the balance between polymerization and depolymerization reactions is $\mathrm{pH}$ and aeration dependent. Under highly alkaline conditions and strong aeration, depolymerization prevailed over polymerization (data not shown).

We were further able to separate lignin fractions with defined molecular weight and low dispersity. Dried lignin fractions have district appearances. Notably, lignin fraction of $>10-\mathrm{kDa}$ molecular weight (L2.1 in Figure 5) shows a clear directional drying pattern and appears as stripes and elongated flakes, as opposed to the full sample (L2 in Figure 5), which dries as small rounded grains. Our results also show that $2-\mathrm{kDa}$ cutoff membrane allows for separation of predominantly monomeric lignin.

Importantly, the absence of organic solvents in the reaction mixture allowed for utilization of polymer-based ultrafiltration membranes, which are widely used in food industry, making scalable and economically feasible. Ultrafiltration membranes of different cutoff are available and widely used in industry. The choice of membranes used in this study was rather arbitrary and can be tuned to the targeted lignin size.

The mechanism of lignin oxidation by bacterial laccases was thoroughly described by Rosado et al. (2012). As opposed to fungal laccases that oxidize the phenolic substrates in the phenolic form, bacterial laccases oxidize them optimally in the phenolate form, i.e., after deprotonation of the phenolic group. Structurally, this is due to the fact that bacterial laccases (such as COTA) do not contain any negatively charged residue in the vicinity of the substrate binding site, and the efficiency of the oxidation of phenols rely mostly on the protonation/deprotonation state equilibria of the compounds themselves. Thus, oxidation is strictly dependent on the chemical nature of the substrates themselves, i.e., on their $\mathrm{pKa}$ values.

The $\mathrm{pKa}$ values of phenolic mediators such as syringaldehyde, acetosyringone, and methyl syringate lie between 7 and 9. This outlines the range where bacterial laccases could be effective in oxidizing lignin via a mediator. However, pKa of phenolic groups in lignin itself is in the range of 10-11. This makes lignin poorly soluble at $\mathrm{pH}$ values substantially lower than this range and also prevents or largely impedes direct oxidation of lignin phenolics by a bacterial laccase. Therefore, reaction conditions exploited in this study open a whole new mode of operation for enzymatic lignin oxidation.

Another important aspect of laccase-mediated oxidation of lignin is that not only it considerably changes molecular weight of the molecules but also changes its properties. Significant increase in water solubility of enzyme-treated lignin was observed even at neutral and acidic $\mathrm{pH}$ as illustrated in Figure 3B. Paralleled to this, enzyme-treated lignin demonstrated altered behavior of in acid titration. It showed a specific span of buffering capacity at $\mathrm{pH} 7-8$, that was absent in the control sample, indicating the appearance of new moieties with $\mathrm{pKa}$ in this range.

To interpret this observation, one has to revert to the reaction mechanism of enzymatic lignin oxidation. According to various scenarios following the radical transfer from the mediator to a lignin unit (phenolic or non-phenolic), reported in previous works, one of the major outcomes of this process is benzylic oxidation resulting in a ketone (or aldehyde) groups at the alphacarbon of the lignin unit (Figure 6). Further chemical scenarios elucidated from the experiments with lignin model compounds mainly revolve around the spacer between benzylic units where the oxidized alpha-carbon is residing (Lahtinen et al., 2009; Ohashi et al., 2011) and little attention is paid to the para-position of the phenyl group connected to this alpha-carbon ( $\mathrm{C} 4$ position of the same benzene ring). Rightfully so, as in acidic $\mathrm{pH}$, where conventional laccases are operating, that position is not yielding any pathways of interest. However, in alkaline $\mathrm{pH}$, this position gains importance. 
A
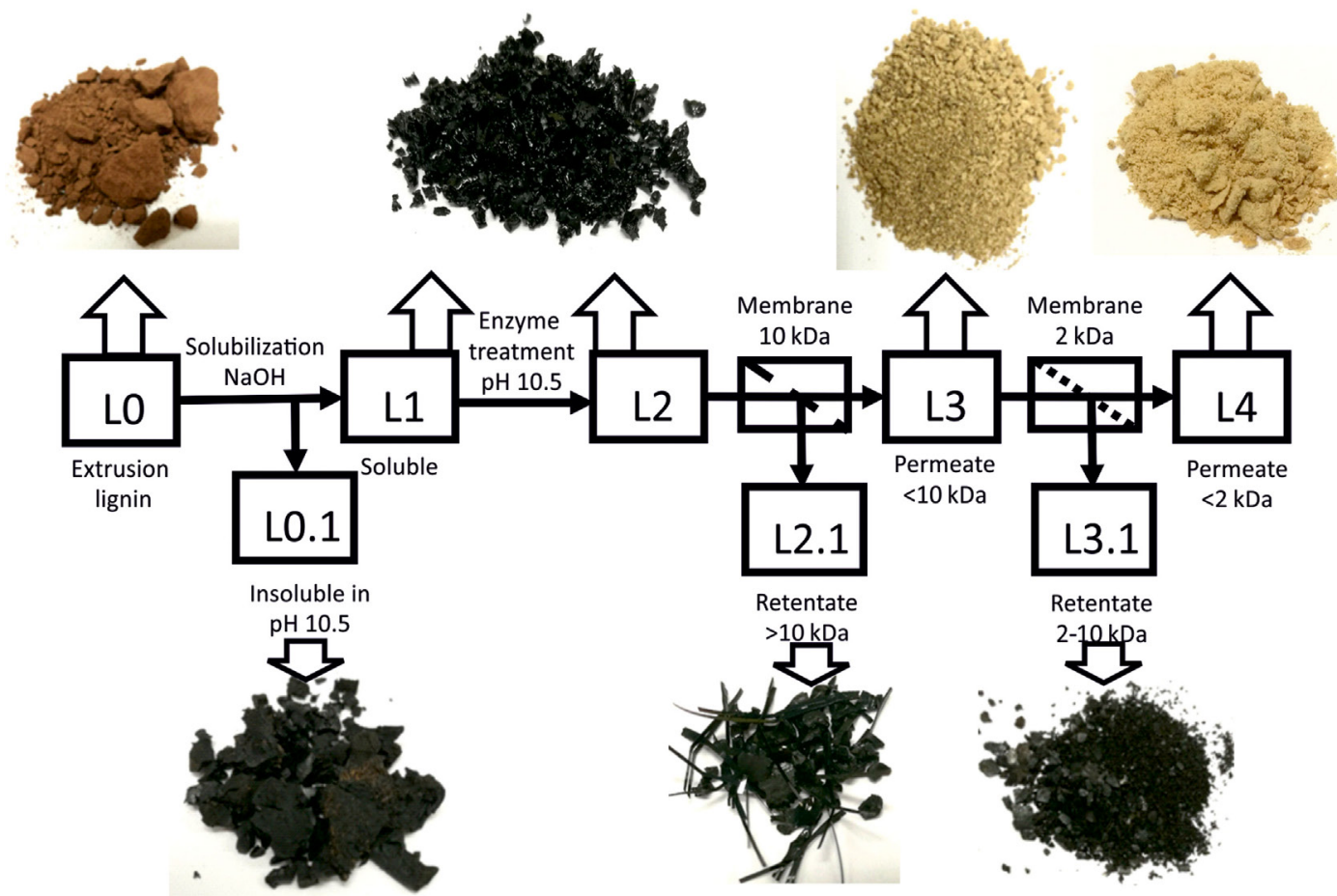

B

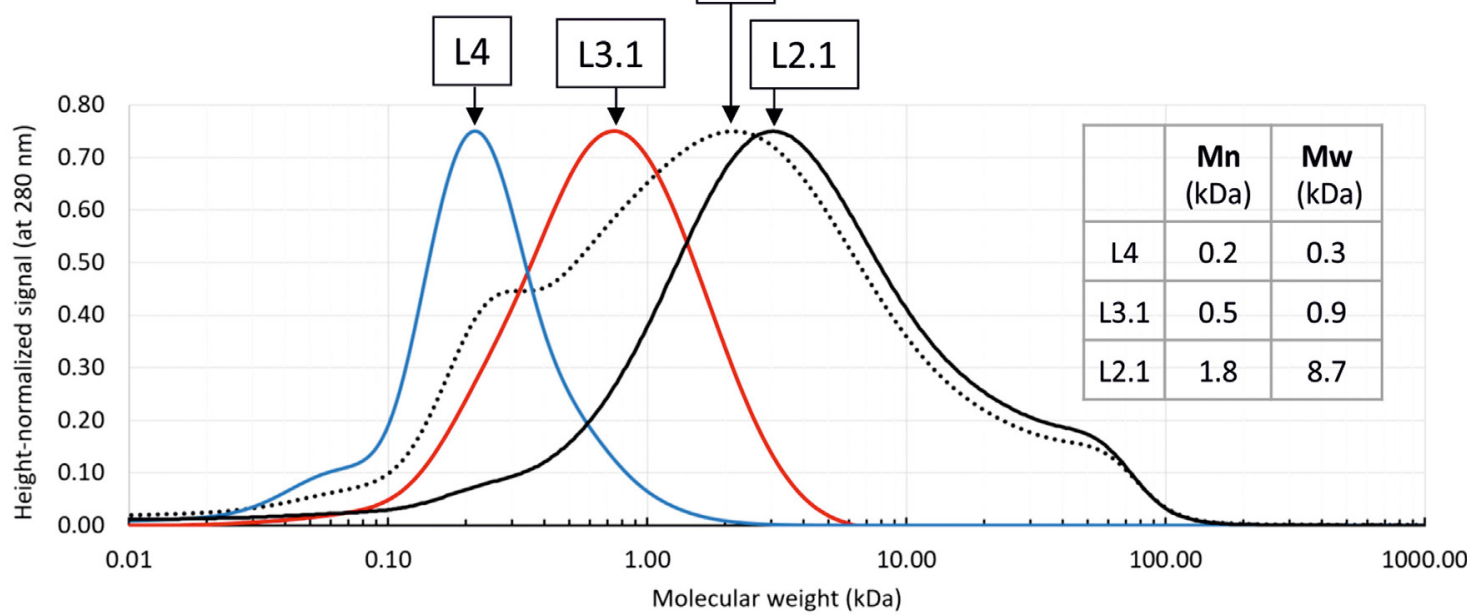

FIGURE 5 | Fractionation of enzyme-treated lignin. (A) Experiment flow chart and lignin fractions (dried); (B) analysis of lignin fractions by size exclusion chromatography. Calculated average molecular weights are given in the table. Since claimed column resolution range is 100-100,000 Da, and molecular weight standards range starts from $600 \mathrm{Da}$, smaller molecular weights may not be calculated correctly.

TABLE 1 | Valorization of lignin by oxidative upgrade and fractionation.

\begin{tabular}{|c|c|c|c|c|c|}
\hline & Molecular weight & $\begin{array}{l}\text { Reactivity and } \\
\text { solubility }\end{array}$ & Application & Bioequivalent of & $\begin{array}{l}\text { Approximate of the } \\
\text { oil-based chemical }\end{array}$ \\
\hline Pulp and paper lignin & $5-100 \mathrm{kDa}$ & Poor & Burning & Oil/electricity & $50-150 € /$ ton \\
\hline Dissolved lignin/biorefinery lignin & $3-50 \mathrm{kDa}$ & Medium & Resins and adhesives & Formaldehyde & $400-500 € /$ ton \\
\hline Enzyme depolymerized lignin & $0.3-2 \mathrm{kDa}$ & Good & Foams and composites & PVA & $1,000-1,500 € /$ ton \\
\hline Enzyme depolymerized fractions & $0.3,0.5,0.7, \ldots, 2 \mathrm{kDa}$ & Very good & New materials & $\begin{array}{l}\text { Specialty chemicals } \\
\text { and polymers }\end{array}$ & $>1,500 € /$ ton \\
\hline
\end{tabular}


<smiles>CCOc1cc(C(C)O)cc(OC)c1OCC</smiles>

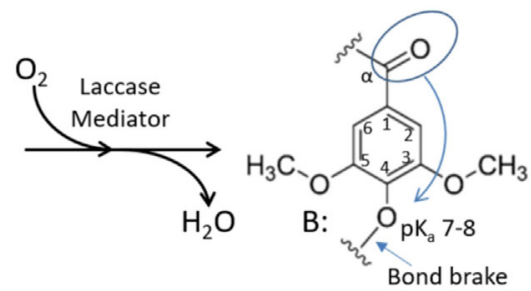

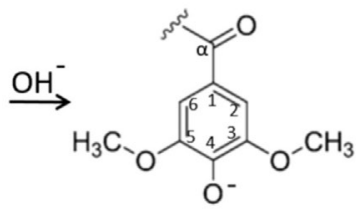<smiles>COc1cc(C(O)CCCCOc2ccccc2)cc(OC)c1O</smiles>

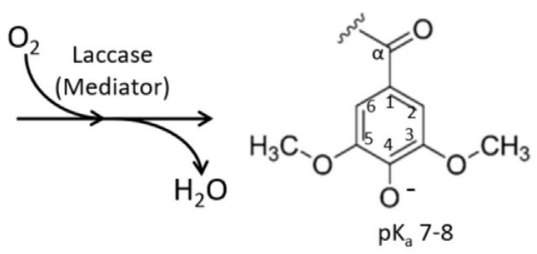

FIGURE 6 | Schematic representation of laccase driven oxidation of a lignin unit. Oxidation of alpha-carbon to a ketone lowers pKa of the corresponding C1 hydroxyl, resulting in increased solubility in neutral-to-acidic $\mathrm{pH}$ and facilitated lignin chain brake.

Ragnar et al. (2000) reported pKa values for phenolic C4 hydroxyls for over 50 different lignin model compounds including monomers and dimers with various substituents at $\mathrm{C} 1$. This remarkable data collection clearly shows that $\mathrm{pKa}$ of the $\mathrm{C} 4$ phenolic hydroxyl remains in very alkaline region (between 9.5 and 11) practically in any environment of the corresponding $\mathrm{C} 1$ atom, apart from alpha-carbon being in the form of a ketone or aldehyde (which is the case upon laccase oxidation). In the later situation, pKa of C4 hydroxyl drops to a value between 7 and 8. This could explain the buffering of oxidized lignin at this $\mathrm{pH}$ range as well as increased solubility at neutral-to-acidic $\mathrm{pH}$. This is because in oxidized phenolic units, $\mathrm{C} 4$ hydroxyl would tend to remain deprotonated at lower $\mathrm{pH}$ (Figure 6). Another implication of this shift in $\mathrm{pKa}$ is that the corresponding alpha-carbon oxidized non-phenolic unit with an ether bond at C4 carbon (Figure 6 top) represents a good leaving group (Boyd, 1985) and may promote lignin chain brake (Figure 6 top, right) or demethylation event.

At the same time, increased number of other types of phenolic units in the oxidized lignin is reflected by the expanded buffering capacity at $\mathrm{pH}$ 9-11 (Figure 3A). In the enzyme-treated sample, the acid consumption in this $\mathrm{pH}$ range was increased by $0.5 \mathrm{mmol} / \mathrm{g}$ of lignin, which coincides with the degree of demethylation determined by methanol detection. In this respect, titration curve of the control sample is in agreement with lignin specification obtained from the manufacturer $(1.5 \mathrm{mmol} / \mathrm{g}$ of total aromatic hydroxyls), confirming our interpretation.

This study is not focusing on polymerization of lignin using laccase; however, we did observe re-polymerization of the shorter molecules when $\mathrm{pH}$ is lowered, especially under limiting aeration. Under these conditions, the reaction was apparently driven

\section{REFERENCES}

Abdelaziz, O. Y., Brink, D. P., Prothmann, J., Ravi, K., Sun, M., García-Hidalgo, J., et al. (2016). Biological valorization of low molecular weight lignin. Biotechnol. Adv. 34, 1318-1346. doi:10.1016/j.biotechadv.2016.10.001 more toward polymerization. This also represents an industrial opportunity, as chemically activated high-molecular weight lignin is highly desirable for some high-end bio-based materials. In addition, polymerization may provide a tool for removing small lignins from the process by polymerization followed by sedimentation or filtration. This is certainly an important aspect for future investigation.

Further studies need to be conducted to fully characterize the enzyme-treated lignin in terms of chemical composition and reactive groups as well as its applicability in industrial processes.

\section{AUTHOR CONTRIBUTIONS}

$\mathrm{KB}, \mathrm{VH}$, and AS contributed to enzyme discovery engineering and characterization. TG and $\mathrm{MH}$ contributed to lignin treatment, characterization, and separation. SM contributed in size exclusion chromatography analysis. PI contributed to colloidal particles analysis. BR implemented computational analysis of HPLC data and contributed to enzyme production. KB wrote the manuscript with support of all the coauthors and offered the interpretation of the results. All authors discussed the results and contributed to the final manuscript.

\section{FUNDING}

Funding from ReTAPP (grant agreement No. 691414) and FALCON (grant agreement No. 720918) through the European Union's Horizon 2020 research and innovation program is acknowledged.
Anthon, G. E., and Barrett, D. M. (2004). Comparison of three colorimetric reagents in the determination of methanol with alcohol oxidase. Application to the assay of pectin methylesterase. J. Agric. Food Chem. 52, 3749-3753. doi:10.1021/jf035284w

Boyd, D. B. (1985). Leaving group ability and pKa, in elimination reactions. J. Org. Chem. 50, 885-886. doi:10.1021/jo00206a033 
Essery, M. (2017). First Higher-Value Chemical Derived from Lignin to Hit Market in 2021. Lux Research. Available at: http://www.luxresearchinc.com/ news-and-events/press-releases/read/first-higher-value-chemical-derivedlignin-hit-market-2021

Frost and Sullivan. (2014). High-Value Opportunities for Lignin: Ready for Liftoff. Available at: http://www.frost.com/sublib/display-market-insight. do? id $=290584392$

Gandini, A., and Belgacem, M. N. (2008). "Lignins as components of macromolecular materials," in Monomers, Polymers and Composites from Renewable Resources, eds A. Gandini and M. N. Belgacem (Elsevier Science), 243-271. Available at: https://www.elsevier.com/books/ monomers-polymers-and-composites-from-renewable-resources/ belgacem/978-0-08-045316-3

Gouveia, S., Fernández-Costas, C., Sanromán, M. A., and Moldes, D. (2012). Enzymatic polymerisation and effect of fractionation of dissolved lignin from Eucalyptus globulus Kraft liquor. Bioresour. Technol. 121, 131-138. doi:10.1016/j. biortech.2012.05.144

Hahn, V., Mikolasch, A., and Schauer, F. (2014). Cleavage and synthesis function of high and low redox potential laccases towards 4-morpholinoaniline and aminated as well as chlorinated phenols. Appl. Microbiol. Biotechnol. 98, 1609-1620. doi:10.1007/s00253-013-4984-9

Hilburg, S. L., Elder, A. N., Chung, H., Ferebee, R. L., Bockstaller, M. R., and Washburn, N. R. (2014). A universal route towards thermoplastic lignin composites with improved mechanical properties. Polymer 55, 995-1003. doi:10.1016/j.polymer.2013.12.070

Kang, S., Li, X., Fan, J., and Chang, J. (2013). Hydrothermal conversion of lignin: a review. Renewable Sustainable Energy Rev. 27, 546-558. doi:10.1016/J. RSER.2013.07.013

Kim, Y. S., and Kadla, J. F. (2010). Preparation of a thermoresponsive lignin-based biomaterial through atom transfer radical polymerization. Biomacromolecules 11, 981-988. doi:10.1021/bm901455p

Kleinert, M., and Barth, T. (2008). Towards a lignincellulosic biorefinery: direct one-step conversion of lignin to hydrogen-enriched biofuel. Energy Fuels 22, 1371-1379. doi:10.1021/ef700631w

Lahtinen, M., Kruus, K., Heinonen, P., and Sipilä, J. (2009). On the reactions of two fungal laccases differing in their redox potential with lignin model compounds: products and their rate of formation. J. Agric. Food Chem. 57, 8357-8365. doi:10.1021/jf901511k

Lange, H., Decina, S., and Crestini, C. (2013). Oxidative upgrade of lignin - recent routes reviewed. Eur. Polym. J. 49, 1151-1173. doi:10.1016/j.eurpolymj.2013. 03.002

Laurichesse, S., and Avérous, L. (2014). Chemical modification of lignins: towards biobased polymers. Prog. Polym. Sci. 39, 1266-1290. doi:10.1016/j.progpolymsci. 2013.11.004

Lux. (2014). Finding Untapped Value: Converting Lignin to Higher Value Chemicals. Available at: https://members.luxresearchinc.com/research/report/14807

Ma, R., Hao, W., Ma, X., Tian, Y., and Li, Y. (2014). Catalytic ethanolysis of Kraft lignin into high-value small-molecular chemicals over a nanostructured $\alpha$-molybdenum carbide catalyst. Angew. Chem. Int. Ed. Engl. 53, 7310-7315. doi:10.1002/anie.201402752

Mate, D. M., and Alcalde, M. (2014). Laccase engineering: from rational design to directed evolution. Biotechnol. Adv. 33, 25-40. doi:10.1016/j.biotechadv.2014. 12.007

Mate, D. M., and Alcalde, M. (2017). Laccase: a multi-purpose biocatalyst at the forefront of biotechnology. Microb. Biotechnol. 10, 1457-1467. doi:10.1111/1751-7915.12422

Munk, L., Sitarz, A. K., Kalyani, D. C., Mikkelsen, J. D., and Meyer, A. S. (2015). Can laccases catalyze bond cleavage in lignin? Biotechnol. Adv. 33, 13-24. doi:10.1016/j.biotechadv.2014.12.008

Nistor, M., Chirila, O., Cazacu, G., Totolin, M. I., and Vasile, C. (2014). Solution properties of some modified lignins. Cell. Chem. Technol. 48, $855-862$.
Ohashi, Y., Uno, Y., Amirta, R., Watanabe, T., Honda, Y., and Watanabe, T. (2011) Alkoxyl- and carbon-centered radicals as primary agents for degrading non-phenolic lignin-substructure model compounds. Org. Biomol. Chem. 9, 2481-2491. doi:10.1039/c0ob00797h

Passoni, V., Scarica, C., Levi, M., Turri, S., and Griffini, G. (2016). Fractionation of industrial softwood Kraft lignin: solvent selection as a tool for tailored material properties. ACS Sustainable Chem. Eng. 4, 2232-2242. doi:10.1021/ acssuschemeng.5b01722

Picart, P., Liu, H., Grande, P. M., Anders, N., Zhu, L., Klankermayer, J., et al. (2017). Multi-step biocatalytic depolymerization of lignin. Appl. Microbiol. Biotechnol. 101, 6277-6287. doi:10.1007/s00253-017-8360-z

Ragnar, M., Lindgren, C. T., and Nilvebrant, N.-O. (2000). pKa-values of guaiacyl and syringyl phenols related to lignin. J. Wood Chem. Technol. 20, 277-305. doi:10.1080/02773810009349637

Rehmann, L., Ivanova, E., Gunaratne, H. Q. N., Seddon, K. R., and Stephens, G. (2014). Enhanced laccase stability through mediator partitioning into hydrophobic ionic liquids. Green Chem. 16, 1462-1469. doi:10.1039/c3gc42189a

Rinaldi, R., Jastrzebski, R., Clough, M. T., Ralph, J., Kennema, M., Bruijnincx, P. C. A., et al. (2016). Paving the way for lignin valorisation: recent advances in bioengineering, biorefining and catalysis. Angew. Chem. Int. Ed. Engl. 55, 8164-8215. doi:10.1002/anie.201510351

Roberts, V. M., Stein, V., Reiner, T., Lemonidou, A., Li, X., and Lercher, J. A. (2011). Towards quantitative catalytic lignin depolymerization. Chemistry 17, 5939-5948. doi:10.1002/chem.201002438

Rodgers, C. J., Blanford, C. F., Giddens, S. R., Skamnioti, P., Armstrong, F. A., and Gurr, S. J. (2010). Designer laccases: a vogue for high-potential fungal enzymes? Trends Biotechnol. 28, 63-72. doi:10.1016/j.tibtech.2009.11.001

Rosado, T., Bernardo, P., Koci, K., Coelho, A. V., Robalo, M. P., and Martins, L. O. (2012). Methyl syringate: an efficient phenolic mediator for bacterial and fungal laccases. Bioresour. Technol. 124, 371-378. doi:10.1016/j.biortech.2012.08.023

Roth, S., and Spiess, A. C. (2015). Laccases for biorefinery applications: a critical review on challenges and perspectives. Bioprocess Biosyst. Eng. 38, 2285-2313. doi:10.1007/s00449-015-1475-7

Santhanam, N., Vivanco, J. M., Decker, S. R., and Reardon, K. F. (2011). Expression of industrially relevant laccases: prokaryotic style. Trends Biotechnol. 29, 480-489. doi:10.1016/j.tibtech.2011.04.005

Singh, G., Kaur, K., Puri, S., and Sharma, P. (2015). Critical factors affecting laccase-mediated biobleaching of pulp in paper industry. Appl. Microbiol. Biotechnol. 99, 155-164. doi:10.1007/s00253-014-6219-0

Smith, P., Chen, M., and Cline, S. (2016). Biorefinery Value Chain Outputs. Available at: https://nararenewables.org/documents/2017/02/155205-nara-biorefineryvalue-chain-outputs-vcea-b-p2.pdf

Wong, D. W. S. (2009). Structure and action mechanism of ligninolytic enzymes. Appl. Biochem. Biotechnol. 157, 174-209. doi:10.1007/s12010-008-8279-Z

Xing, Q., Ruch, D., Dubois, P., Wu, L., and Wang, W.-J. (2017). Biodegradable and high-performance poly(butylene adipate-co-terephthalate)-lignin UV-blocking films. ACS Sustainable Chem. Eng. 5, 10342-10351. doi:10.1021/ acssuschemeng.7b02370

Yoshikawa, T., Taichi, Y., Satoshi, S., Tetsuya, F., Yuta, N., Teruoki, T., et al. (2013). Production of phenols from lignin via depolymerization and catalytic cracking. Fuel Process. Technol. 108, 69-75. doi:10.1016/j.fuproc.2012.05.003

Conflict of Interest Statement: VH, TG, AS, MH, BR, PI, and KB were employed by the company MetGen Oy. All other authors declare no competing interests.

Copyright ( 2018 Hämäläinen, Grönroos, Suonpää, Heikkilä, Romein, Ihalainen, Malandra and Birikh. This is an open-access article distributed under the terms of the Creative Commons Attribution License (CC BY). The use, distribution or reproduction in other forums is permitted, provided the original author(s) and the copyright owner are credited and that the original publication in this journal is cited, in accordance with accepted academic practice. No use, distribution or reproduction is permitted which does not comply with these terms. 